\title{
Disputas en torno al territorio en la subregión de Tierradentro. Un abordaje de larga duración
}

\begin{abstract}
Disputes around the territory in the subregion of Tierradentro.
\end{abstract}
A long-term approach

Sebastián Levalle*

Resumen: Este trabajo aborda la resistencia a la violencia política del pueblo nasa de Tierradentro, Colombia, desde un enfoque sociohistórico de larga duración. Se identifican las estrategias bajo las cuales se ha desplegado dicha resistencia en diversas coyunturas y se analiza la emergencia del Consejo Regional del Cauca. El trabajo postula que los nasa han enfrentado la violencia política desplegando un proceso de recreación de la territorialidad comunitaria. Este proceso es desagregado en cuatro dimensiones que presentan su propia historicidad.

Palabras Clave: Violencia; Resistencia; opresión; Conflicto étnico; Sociología histórica; Colombia

\begin{abstract}
This paper addresses the resistance to political violence of the Nasa people of Tierradentro, Colombia, from a long-term sociohistorical approach. The strategies under which this resistance has been deployed at various junctures are identified and the emergence of the Regional Council of Cauca is analyzed. The work postulates that the Nasa have faced political violence undertaking a process of recreation of the community territoriality. This process is disaggregated into four dimensions that present their own historicity.
\end{abstract}

Keywords: Violence; Resistance; Oppression; Ethnic conflict; Historical sociology; Colombia

Recibido: 19 agosto 2018 Aceptado: 4 octubre 2018

\section{Introducción}

A pesar de que la sociología colombiana sobre la violencia política ha contribuido desde mediados del siglo pasado a los estudios a gran escala típicos de la tradición sociohistórica, los trabajos más recientes han tomado un giro regionalista. En los últimos años la resistencia que el pueblo nasa ha desplegado en el departamento del Cauca ha resultado objeto de varios análisis. Sin embargo, la subregión de Tierradentro, la zona con mayor cantidad de resguardos y de cabildos indígenas de este departamento,

\footnotetext{
* Argentino. Magíster en Estudios Sociales Latinoamericanos, Lic. en Sociología. Becario doctoral del CONICET con sede en el Instituto de Estudios de América Latina (UBA) y el Caribe y docente de la Universidad de Buenos Aires y de la Universidad Nacional de José C. Paz. Este trabajo ha contado con el apoyo financiero del Proyecto de Investigación Plurianual (2014-2016) "Condiciones sociohistóricas de la violencia rural en América Latina”, 1950s1990s, CONICET. Correo electrónico: slevalle@yahoo.com.ar
} 
ha permanecido menos estudiada. El carácter económicamente marginal y la configuración de esta zona como territorio de alteridad, han contribuido a la consolidación de abordajes históricos espasmódicos. Salvo algunas excepciones (vg. Rappaport 1990), dichos trabajos suelen concentrarse en el período colonial o en los inicios del siglo XX, sin lograr articular el pasado reciente en una línea de larga duración.

En el desarrollo de este trabajo analizo la resistencia a la violencia política del pueblo nasa de Tierradentro desde un enfoque sociohistórico de larga duración. El enfoque sociohistórico permite observar los efectos de las grandes estructuras y los procesos de cambio social de medio y largo aliento (Ansaldi 2002; Skocpol 1991; Tilly 1991). Desde esta perspectiva, el tiempo es mucho más que un conjunto de datos contextuales del problema de investigación; el tiempo representa una variable explicativa que afecta el cómo sucedieron los acontecimientos (Tilly 1991: 29). El abordaje de larga duración me ha permitido identificar una serie de coyunturas en las cuales la resistencia indígena a la violencia política en Tierradentro ha adoptado distintas estrategias.

Tierradentro se ubica en la vertiente oriental de la Cordillera Central. Administrativamente, está conformada por los municipios de Inzá y Páez pertenecientes al departamento del Cauca. Siguiendo a Sánchez, Vargas y Vásquez $(2011,31)$, considero a Tierradentro como una subregión dentro de la región andina del suroccidente colombiano. Tierradentro está habitada por alrededor de 30.000 indígenas, equivalente al $56 \%$ de la población subregional. La mayor parte de los indígenas de esta subregión pertenecen al pueblo nasa. El pueblo nasa se compone de 186.178 personas, de las cuales un $88,6 \%$ vive en el departamento del Cauca junto a otros nueve grupos indígenas (DANE 2005). De acuerdo con mis interlocutores indígenas, las comunidades indígenas se identifican con la población que habita en resguardos legalmente constituidos y se rigen bajo la autoridad de un cabildo. El cabildo es la autoridad administrativa y de gobierno en los territorios de resguardos, en tanto que el resguardo es una figura de origen colonial que identifica la posesión colectiva de la tierra.

Para el análisis del pasado reciente (1971-2015) en Tierradentro realicé 13 entrevistas a militantes de las instancias locales y regionales del CRIC. Complementariamente, utilicé documentos de la organización indígena disponibles en el Centro de Documentación José María Ulcué en la ciudad de Popayán. Para medir la evolución de la violencia política acudí a las bases de datos del Centro de Recursos para el Análisis de Conflictos (CERAC) y de la Revista Noche y Niebla, ambas disponibles en Internet. Los datos sobre distribución y calidad de la tierra fueron construidos a partir de las bases de datos del equipo Territorio y Naturaleza de la asociación Nasa Çxhâçxa.

\section{Violencia política y resistencia indígena en Tierradentro: desde la colonización hasta la fundación del CRIC}

En aras de comprender el desarrollo de la resistencia del pueblo nasa, se hace necesario analizar brevemente la configuración histórica de esta subregión. Acorde Ansaldi y Alberto (2014), la violencia política se orienta a producir o inhibir cambios en la estructura del poder y puede ser realizada por el Estado, por organizaciones paralegales, o por organizaciones insurgentes. Recuperando las premisas de la sociología clásica, Ansaldi y Giordano (2012) plantean que la violencia política resulta un elemento constitutivo de todo proyecto de orden social. El orden social es una construcción sociohistórica que resulta del conflicto, es la expresión concreta del poder entendido como relación de fuerzas sociales.

Como he postulado en otro trabajo (Levalle, 2018), esta violencia puede ser analizada en función de tres dimensiones centrales. En primer lugar, siguiendo a Galtung (1998), es posible identificar una dimensión estructural, que es aquella en la que las mediaciones institucionales o estructurales impiden el acceso a los recursos y oportunidades de vida. En el ámbito rural esta primera dimensión se expresa en la concentración de la tierra. En segundo lugar, ubico la violencia política armada, que es aquella que despliega un grupo organizado militarmente para cuestionar el poder del Estado o para combatir a los grupos insurgentes. Finalmente, la dimensión epistémica de la violencia política es aquella que se ejercita 
a partir de la imposición de regímenes de saber (Foucault 2007) que se orientan al control de los sujetos sociales. Esta forma de violencia simbólica impone y legitima los significados y los valores hegemónicos y subalterniza los conocimientos no hegemónicos. La dimensión epistémica de la violencia política adquiere una relevancia especial bajo situaciones de colonialidad como las que viven las sociedades indígenas latinoamericanas.

Recuperando los trabajos de Michel Foucault (1986), sitúo la resistencia dentro del juego de las fuerzas sociales que se articula en torno al poder. La resistencia, como el poder, existe en tanto despliegue de relación de fuerzas. Si el objetivo del poder es administrar la existencia humana, la resistencia aparece en distintos puntos del entramado social como fuerza resistente frente al poder que intenta dominarla. A diferencia de conceptos como empoderamiento o lucha, la noción de resistencia implica un antagonismo específico (Grossberg 1992, 52), supone la capacidad de oponerse a la fijación de las relaciones sociales en relaciones de dominación. Las fuerzas que resisten se encuentran en el interior de las relaciones estratégicas, son coextensivas al poder. Sin embargo, Foucault (2000) ha sugerido que la resistencia no implica únicamente una posición invertida respecto del poder; por el contrario, ella puede expresarse creativamente, como un proceso activo de transformación. Existen momentos en los cuales la resistencia se expresa de forma activa, incluso con recurso a la violencia. Sin embargo, los trabajos que desde los años ochenta abordan las rebeliones indígenas del espacio andino han enfatizado la necesidad de desarrollar análisis de larga duración capaces de mostrar la articulación entre los períodos de insurrección abierta y los de "adaptación en resistencia" (Stern 1987, 33). En estos últimos casos, la resistencia involucra la acción política innovadora de los indígenas para tratar de comprometer al Estado, sin cuestionar integralmente el sistema de dominación.

A la llegada de los conquistadores ibéricos, Tierradentro constituía una frontera para el pueblo nasa, que tenía su centro político en la ciudad de La Plata. Los nasa arribaron a Tierradentro en el siglo XVI, los asentamientos allí eran de naturaleza multiétnica y se organizaban bajo un patrón de poblamiento disperso (Rappaport 1990). Esta organización social descentralizada dificultó la penetración colonial; también desde la mirada blanca Tierradentro apareció como un territorio de frontera. La extensión de la resistencia indígena, sumada a las dificultades geográficas para el acceso al territorio, quedaron plasmadas en la denominación que los soldados de Sebastián de Belalcázar emplearon para nombrar este territorio, al que llamaron "las montañas de la Tierradentro" (Asociación de cabildos Juan Tama 2005).

La lucha contra los conquistadores se extendió en esta subregión a lo largo de más de un siglo (1536-1651). Sin embargo, no fueron los adelantados sino los misioneros católicos quienes lograron penetrar efectivamente en el territorio nasa. La resistencia indígena durante este período explica el desarrollo tardío de la encomienda, que comienza allí en 1620, casi un siglo después que en el resto del reino de Nueva Granada (Rappaport 1990). Hacia 1640 los padres jesuitas, que habían llegado a Tierradentro en 1613, se debieron retirar por la oposición indígena. Pero desde 1682 los franciscanos, y desde 1689 los padres seculares, consiguieron asentarse en el territorio.

El orden colonial se estructuró desde el siglo XVII alrededor de la conformación de espacios de segregación bajo los cuales se estableció un control biopolítico del conjunto del cuerpo social (Gnecco 2006). Para controlar la diferencia, explica Gnecco, fue necesario localizarla territorialmente. Los pueblos de indios concentraron la población indígena para facilitar el pago de tributos y el pago de servicios a particulares, la Iglesia y el Estado, y modificaron el patrón de poblamiento disperso bajo el cual se organizaban los nasa. Instaurada la dominación colonial se establecieron saberes, prácticas e instituciones encargadas de gobernar a las poblaciones indígenas. Instituciones como el reparto de indios o la imposición de tributos y servicios personales, y prácticas como el despojo de los territorios, la evangelización, el desconocimiento de las autoridades tradicionales, el combate armado y la represión materializaron la violencia política sobre el pueblo nasa de Tierradentro (Hernández Delgado 2004; Rappaport 1990).

Las misiones católicas encarnaron la tarea de construcción de la legitimidad que el orden social colonial requería para perdurar en el tiempo. Como ha planteado el propio Foucault (2007b) los atributos 
que la ciencia política clásica suele postular como base de los Estados modernos han sido asumidos históricamente por actores estatales y no estatales. Paola Rodríguez ha llamado la atención acerca de la necesidad de abrir el concepto de Estado en realidades como la colombiana, donde las prácticas ilegales resultan medios privilegiados de construcción de las capacidades estatales (Rodríguez 2016). Frente a este encorsetamiento en la noción de Estado, el concepto de "estatalidad" parece alumbrar mejor las relaciones sociales que reproducen el Estado, incluso, por fuera de sus márgenes. En su tesis doctoral, Miguel Leone (2017) ha mostrado la capacidad heurística de este concepto en territorios constituidos como objeto de misiones eclesiásticas.

En Tierradentro, la presencia eclesiástica se configuró como el patrón de estatalidad fundamental, aunque con el paso del tiempo el ejército, la policía, los partidos políticos y las organizaciones guerrilleras encarnaron prácticas estatales. A su vez, desde 1991, los cabildos han sido forzados a asumir el papel del Estado, tomando control incluso del sistema penal (ver Rappaport 2008). Durante la Colonia, la legitimidad en esta subregión fue construida a partir de dispositivos educadores de corte civilizatorio que, en manos de las autoridades eclesiásticas, subalternizaron a las poblaciones nasa. Los procesos coloniales de construcción de alteridad establecieron un sistema de jerarquías que postulaba a los indígenas como sujetos incompletos a ser educados por la población blanca y española. La violencia epistémica propia de este modelo determinó la subalternización de las prácticas culturales y los sistemas de aprehensión de la realidad que los nasa habían recreado históricamente, ahora demarcados como inferiores frente al corpus de conocimiento europeo (E2; E12).

Hacia fines del siglo XVII la resistencia indígena a la violencia política se desplegó al interior de la lógica colonial, en un proceso de reapropiación crítica de dos instituciones creadas por los conquistadores: el resguardo y el cabildo. En este proceso, ocurrió una inversión de la regulación biopolítica que había animado la constitución colonial de los territorios de resguardo, ya que estos espacios de alterización fueron puestos al servicio de la recreación de las prácticas comunitarias. Los caciques Goyumuses de Togoima (1667), Jacinto Moscay de Pitayó (1696) y Juan Tama de la Estrella (1700) lucharon legalmente por el reconocimiento legal de sus territorios bajo el carácter de resguardo indígena. Estos resguardos fueron peticionados directamente por los líderes indígenas para delimitar claramente su territorio y para fortalecer un modelo regional de autoridad que se enarboló a partir del reconocimiento de la institución hereditaria del cacicazgo principal (Bonilla 1982; Findji y Rojas 1985; Rappaport 1990). De tal forma, en los albores del siglo XVIII el territorio nasa se estructuró en cuatro grandes cacicazgos: Toribío en el norte, Pitayó en el centro, y Togoima y Vitoncó en Tierradentro. De este modo, los líderes nasa lograron defender su territorio y construir una inédita unidad política.

La independencia de la actual Colombia de la Corona española, desde el triunfo de 1819 de Bolívar en Boyacá, no modificó sustancialmente la situación fronteriza de Tierradentro. Tal condición se reprodujo desde la mirada estatal mediante la promulgación de una serie de normas, tales como la firma en 1888 entre el Estado y la Santa Sede de la primera convención con las misiones católicas, con el objeto de colonizar y cristianizar su "periferia" (Rojas y Castillo 2005). Pero al mismo tiempo, durante la mayor parte del siglo XIX, las comunidades nasa de esta subregión y de sus alrededores conservaron una autonomía cultural y política cuidadosamente negociada con las elites caucanas (Lemaitre 2013). Yesenia Pumarada Cruz (2013) argumenta que esta autonomía se sustentó en un conjunto de factores, como son: la relativa inaccesibilidad de sus comunidades, la participación militar de algunos de sus miembros en tres guerras civiles (la Guerra de Independencia, la Guerra de los Supremos de 1839 y la Revolución Liberal de 1860), la articulación de alianzas por parte de los caciques con líderes políticos e integrantes de las clases dominantes del Cauca, y el control legalmente establecido de la mayor parte del territorio comunitario. Se trató de un proceso de "adaptación en resistencia" (Stern 1990) bajo el cual las comunidades nasa se adaptaron al orden postindependentista de un modo estratégico, logrando conservar unos márgenes amplios de autonomía.

Pero con la maduración del orden oligárquico, hacia fines del siglo XIX, los procesos socioeconómicos que operaban como base de las negociaciones perseguidas por los líderes nasa para 
garantizar su autonomía territorial sufrieron importantes transformaciones. Colombia comenzaba a recorrer la transición de una economía minera a una economía agroexportadora y el Cauca jugaba un papel crucial en este proceso. La presión sobre los resguardos se acentuó con el surgimiento de una clase agraria necesitada de mano de obra barata. Como afirma Pumarada Cruz (2013), para poder transformar estos territorios en espacios nacionales debieron antes ser convertidos en espacios coloniales. Tierradentro se vinculó entonces a la economía departamental bajo una lógica de colonialismo interno (González Casanova 1975). En los años setenta González Casanova explicó que en América Latina el colonialismo no ocurre únicamente a nivel internacional, sino que se expresa también al interior de cada espacio nacional. El colonialismo interno combina la discriminación con la explotación semi-colonial y se produce en los terrenos económico, político, social y cultural, articulando las dimensiones de clase y etnia. Las poblaciones nasa de Tierradentro fueron explotadas por las elites de Popayán, que monopolizaban el comercio y el crédito.

El período de dominación oligárquica se consolida en Colombia con el triunfo de los conservadores en la guerra civil de 1885 y se plasma en la Constitución Nacional de 1886, una constitución unitaria y católica. Este proceso en la historiografía nacional será conocido como La Regeneración. Los regeneracionistas buscaron implantar una nación basada en el catolicismo, el blanqueamiento y la unidad lingüística, como se condensa en la máxima de la época: "una nación, un dios". En este marco se dictó la Ley 89 de 1890 "por la cual se determina la manera como deben ser gobernados los salvajes que vayan reduciéndose a la vida civilizada", que pretendía ofrecer un marco regulatorio para la disolución de los resguardos indígenas aún en pie, y entregarles títulos individuales a sus habitantes.

Los procesos coloniales de marcación de la diferencia se reactualizaron mediante la instrumentalización de una nueva "economía política de la diversidad". La antropóloga argentina Claudia Briones (Briones et al. 2006), sostiene que todo Estado nación instrumenta una economía política de la diversidad que etniciza y/o racializa selectivamente distintos colectivos sociales. Es decir que todo Estado Nación reproduce desigualdades internas y renueva consensos en torno a ellas, tematizando ciertas diferencias e invisibilizando otras. Se fijan de este modo marcas y umbrales de uniformidad y alteridad que permiten identificar regularidades en la jerarquización sociocultural de "tipos" de otros internos construidos como parcialmente segregados en base a características supuestamente "propias", pero definidos siempre por una triangulación que los especifica entre sí y los reposiciona respecto del "ser nacional".

Esta operación habilita modos diferenciados de explotación económica y de incorporación político-ideológica de la fuerza de trabajo. La población indígena del Cauca fue sometida a relaciones semiserviles de explotación, como el terraje, por los hacendados que fueron instalándose en las tierras de resguardo. En el norte del departamento el despojo de los territorios indígenas obligó a los nasa a someterse al trabajo bajo patrón en las haciendas. Atraídos por las nuevas oportunidades, grupos de colonos se establecieron en Tierradentro, conformando áreas de población no indígena. Sin embargo, según sostiene Rappaport (1990, 88), no será hasta el final del siglo XIX cuando los latifundistas comiencen a asentarse más sistemáticamente en esta subregión, obligando a las comunidades nasa a desarrollar instituciones políticas propias para resistir la violencia política.

A inicios del siglo XX los hacendados caucanos aumentaron el terraje para consolidar sus propiedades, intensificar los cultivos y expandir la superficie destinada a la producción ganadera. Esta presión motivó a los terrajeros a aliarse políticamente bajo la figura de Manuel Quintín Lame, un terrajero de la hacienda de San Isidro, del departamento del Cauca. Hijo de migrantes ya desvinculados de las parcialidades nasa de los resguardos de Tierradentro, Manuel Quintín Lame resultó ser el líder indígena más importante del Cauca en la primera mitad del siglo XX. Movilizó a las comunidades indígenas del departamento contra los hacendados, los colonos no indígenas y las autoridades locales. Su movimiento, que entre 1912 y 1925 fue conocido como "La Quintiñada" o "La Quintiada", se extendió luego al Huila y al Tolima (Castillo Cárdenas 1971; Lemaitre 2013; Espinoza Arango 2009). A pesar de la dimensión de 
la lucha, sus objetivos no lograron concretarse y los procesos de desintegración de la territorialidad nasa en Tierradentro siguieron su curso ascendente.

Las demandas de Lame, fueron retomadas cuarenta años después en ocasión de la fundación del CRIC. Para la década del setenta del siglo XX, la situación de asedio sobre las comunidades indígenas del Cauca se profundizó. La violencia rural y el bloqueo estadounidense a las exportaciones de azúcar de Cuba favorecieron la expansión de las haciendas. El incremento de la explotación de la fuerza de trabajo indígena y la presión sobre las tierras de resguardo redundaron en un aumento de la concentración de la propiedad rural. El 1,8\% de los propietarios del departamento concentraba el 50\% de las tierras productivas (Peñaranda 2012,142) y una buena parte de los indígenas trabajaba bajo formas semiserviles en las haciendas. Tal era la situación de los indígenas nasa y misak del centro y norte del departamento (ver Findji 1978, 92 y 99), cuya organización derivó en la conformación del CRIC.

La movilización de la población indígena del Cauca encontró nuevas oportunidades políticas en la coyuntura abierta por la activación de la reforma agraria en la segunda mitad del siglo XX. En la línea de las reformas modernizantes impulsadas por la Alianza para el Progreso en el contexto de la Guerra Fría, en 1961 se promulgó la ley 135 que creó el Instituto Colombiano de la Reforma Agraria (INCORA). La reforma agraria promovida por el presidente liberal Carlos Lleras Restrepo se orientó a remover los obstáculos para el desarrollo capitalista en el campo mediante la promoción de un empresariado rural y de granjas campesinas (Albán 2011; CNMH 2012). En el marco de esta ley el gobierno impulsó la organización de los sectores rurales como un medio de presión para que los latifundistas adoptaran la orientación reformista. Así nació la Asociación Nacional de Usuarios Campesinos (ANUC), organización creada por el Estado para nuclear a los usuarios de la reforma agraria en julio de 1970. La ANUC expresó un proyecto de alianza entre la burguesía reformista y el campesinado y logró liderar el movimiento de ocupaciones de tierras más importante de la historia colombiana (Zamosc 1984, 216; Castillo Gómez 2009, 101). El contexto de la reforma agraria posibilitó, además, que un conjunto de intelectuales y activistas políticos se vincularan con los líderes indígenas del Cauca mediante el Instituto Colombiano de la Reforma Agraria (INCORA) y a través de organizaciones campesinas como el Frente Social Agrario (FRESAGRO).

Sin embargo, hacia 1971 la alianza que había cristalizado en la ANUC entró en tensión y las invasiones de tierra se fueron desacelerando. Frente al estancamiento de la reforma agraria, los indígenas caucanos decidieron conformar su propia organización, dando origen al Consejo Regional Indígena del Cauca. Sus impulsores fueron terrajeros sin tierra, en su mayor parte del centro y norte del departamento, agobiados por la situación de sobrexplotación a la que estaban sometidos. El CRIC se conformó como una estructura regional, integrando a las instituciones preexistentes y otorgándoles nuevas funciones (Gros 1991). En lugar de conformar una organización paralela, buscó recuperar la figura del cabildo y pretendió hacer valer los títulos que las autoridades ibéricas habían otorgado a los caciques indígenas. En la segunda asamblea del CRIC, llevada a cabo en Tacueyó el 6 de septiembre de 1971, se acordó un programa de siete puntos básicos:

1. Recuperar la tierra de los resguardos; 2. Ampliar los resguardos; 3. Fortalecer los cabildos indígenas; 4 . No pagar terraje; 5 . Hacer conocer las leyes sobre indígenas y exigir su justa aplicación; 6. Defender la historia, la lengua y las costumbres indígenas; 7. Formar profesores bilingües para educar de acuerdo con la situación de los indígenas y en su propia lengua. (CRIC 1981, 12-13)

El bloqueo de la vía legal para la reforma agraria constituye un elemento fundamental para comprender el modo en el que se desplegaron las luchas indígenas en el Cauca. Después de la relativa apertura hacia las políticas de reforma agraria promovida por el presidente liberal Carlos Lleras Restrepo, las élites rurales instauraron una contrarreforma agraria. El Pacto de Chicoral, firmado por los partidos tradicionales y los gremios de propietarios bajo el gobierno del conservador Misael Pastrana Borrero, 
terminó con la política agraria redistributiva mediante un conjunto de leyes que dilataron los tiempos para la adjudicación de tierras y favorecieron a los grandes propietarios (Fajardo Montaña 2015; Albán 2011). La orientación conservadora de la política estatal sobre la tierra no fue modificada sustancialmente en todo el período 1971-2012, dando por resultado una tendencia histórica a la concentración de la propiedad rural y una desigualdad estructural en el campo (IGAC 2012).

La "recuperación" de tierras apareció como el "repertorio de movilización" (Tilly 1998) privilegiado. Mientras que el Estado y los terratenientes denunciaron estas acciones como "invasiones" a la propiedad privada (Castillo Gómez 2009), los pueblos indígenas del Cauca las concibieron como un proceso largo de recuperación de los territorios ilegítimamente usurpados por los hacendados desde los tiempos de la Colonia. Las recuperaciones se iniciaron en el centro oriente del departamento, para 1972 se desplazaron hacia el sur oriente y luego se generalizaron de forma incontenible.

Tierradentro era entonces una región de policultivos en pequeña escala orientados al autoconsumo, con lento avance de la propiedad privada (Findji 1978). Cuando se fundó el CRIC, esta era la zona con mayor cantidad de resguardos y de cabildos indígenas (CRIC 1990, 4). La subsistencia de 18 resguardos en esta subregión se explica por la resistencia indígena desde los tiempos coloniales y por la escasa utilidad marginal de la tierra. Ambos factores habían limitado la radicación de hacendados en Tierradentro. Por eso, en esta subregión las recuperaciones fueron menos extendidas que en el norte y centro del Cauca donde se concentraba la producción cañera para el mercado interno, factor determinante en la desintegración de los resguardos.

El Estado Nacional había establecido a Tierradentro como territorio de misión en 1903, asumiendo que allí habitaban poblaciones primitivas necesitadas del tutelaje católico. Este estatuto territorial se amparaba en las prerrogativas de la Constitución Nacional de 1886 y de la convención con las misiones católicas que el Estado había firmado en 1888. Bajo la conformación del territorio de misión, la iglesia logró conservar el control de la educación en Tieradentro -una atribución que mantuvo hasta el 2010. Axel Rojas y Elisabeth Castillo (2005) sostienen que, en las zonas de periferia, como Tierradentro, se estableció un modelo de "iglesia docente" que estructuró un modo de administrar las poblaciones racializadas/etnicizadas, designadas como otros internos de la nación. La naturalización de las jerarquías sociales mediante los diacríticos raza/etnia fue internalizada en los propios dispositivos de conocimiento y reproducida por las instituciones escolares.

En el norte del Cauca, sacerdotes como Pedro León Rodríguez y Álvaro Ulcué Chocué, asesinado en 1984 a manos de grupos paralegales, jugaron un papel favorable a la organización indígena (ver Roattino 1986). Pero el Vicariato Apostólico de Tierradentro profesó una orientación conservadora desde su creación. Como recuerda Arnulfo Guegia, que formó parte de la asociación de cabildos Juan Tama, "el enemigo más grande que surgió para la iglesia fue el CRIC" (E1). El prefecto apostólico entre 1950 y 1977, Enrique Vallejo, y su sucesor hasta 1988, Germán García Isaza, junto a los políticos tradicionales y los terratenientes mantuvieron una celosa alianza contra las demandas y las luchas indígenas. Por eso, en sus comienzos, el CRIC tuvo una presencia intermitente y clandestina en esta zona (E11).

La oposición de estos sectores obligó a mudar el tercer congreso del CRIC desde Tierradentro hacia Silvia, en la zona oriental. Sin embargo, en 1972 el INCORA y el Departamento Administrativo Nacional de Estadística (DANE) acordaron con el CRIC la realización del primer Censo Indígena. En este proceso, los activistas del CRIC lograron penetrar en Tierradentro y difundir el programa de los siete puntos y las actividades de la organización (CRIC 1981, 18; CRIC 1990, 5). La organización indígena logró hacer por primera vez un congreso en Tierradentro, en el resguardo de Tóez, en 1975. Para fines de este segundo año, el CRIC alcanzó a todas las zonas con presencia indígena.

Desde mediados de los años cincuenta, la violencia política armada desarrolló y reconfiguró las tensiones producto de la violencia estructural y epistémica. Guerrillas, carteles de la droga y grupos paramilitares han librado una lucha por el control del territorio, los recursos y la población (González, Bolívar y Vásquez 2002) que ha impactado en los territorios de las comunidades indígenas caucanas con 
particular intensidad (Base de datos CERAC y Noche y Niebla). La presencia guerrillera en el Cauca involucra prácticamente a la totalidad de los grupos insurgentes, tanto los llamados "históricos" como los de "segunda generación". Esta presencia obedece a razones geopolíticas -relacionadas con la inaccesibilidad y los lazos comunicantes con otros departamentos- y estratégicas -en función del aprovechamiento del conflicto social entre las haciendas y los sectores campesino indígenas- (Peñaranda 2012, 173). Para enfrentar a estos grupos desembarcaron desde 1999 las Autodefensas Unidas de Colombia, el mayor ejército paralegal. Desde la fundación del CRIC la resistencia indígena a la violencia política ha implicado el asesinato de alrededor de 500 dirigentes por parte de fuerzas militares, grupos paralegales y guerrillas (CRIC 2011).

Si bien desde los años sesenta Tierradentro se constituyó como una de las zonas de influencia histórica de las Fuerzas Armadas Revolucionarias de Colombia (FARC), en el período de estudio de este trabajo la subregión presentó un bajo nivel de violencia asociada al conflicto armado. A diferencia del resto del departamento del Cauca, en los municipios de Páez e Inzá no se registraron masacres, ni acciones masivas de desplazamiento forzado desde 1990. Del conjunto de las fuerzas insurgentes que actuaron en el Cauca, solamente tuvieron presencia permanente los frentes VI y Jacobo Arenas de las FARC y, residualmente, el Ejército de Liberación nacional (ELN). Tampoco se registraron acciones de envergadura de los grupos paralegales (Base de datos CERAC y Noche y Niebla). Las "Águilas Negras" fueron el grupo paralegal con mayor visibilidad, pero generalmente su accionar se limitó a la persecución política por medio de la difusión de listas negras (E1 y E8).

Las causas de la baja intensidad del conflicto armado en Tierradentro se relacionan con tres factores: (a) la efectividad de la estrategia de resistencia de las comunidades indígenas; (b) la inexistencia de cultivos ilícitos entre 2001 y 2007 (Sistema Integrado de Monitoreo de Cultivos Ilícitos -SIMCI-), lo cual explica parcialmente la ausencia de paramilitares; y (c) la escasa importancia estratégica de la subregión en la economía ilegal -no es un corredor estratégico, sus vías no están pavimentadas y tiene territorios minados- que se traduce en la inexistencia de un esquema de beneficios claros como para que otro grupo armado dispute la hegemonía de las FARC en la subregión (Sánchez, Vargas y Vásquez 2011).

A pesar de la menor incidencia del conflicto armado en esta zona, el trabajo de campo permite demostrar que la violencia política armada continúa afectando a las comunidades de Tierradentro. Las instancias locales del CRIC han enfrentado la pretensión hegemónica de las FARC y la instalación de bases militares por parte de las fuerzas armadas estatales. El desplazamiento forzado, que desde 1985 ha alcanzado a 9951 personas (Registro Único de Víctimas), y la utilización de las comunidades como base de reclutamiento por parte de los ejércitos enfrentados en el conflicto armado interno configuran sendas amenazas a la recreación de la territorialidad comunitaria que defienden las instancias locales del CRIC en Tierradentro.

Como resultado del análisis precedente es posible identificar cuatro coyunturas fundamentales en las cuales se expresó la resistencia a la violencia política del CRIC en Tierradentro. En un primer momento, durante la lucha contra los conquistadores ibéricos, la resistencia se practicó de forma abierta, permitiendo demorar la penetración colonial. En una segunda instancia, los caciques nuevos desarrollaron un proceso de adaptación en resistencia que sirvió para cohesionar el territorio, cimentando el sentido actual que esta zona posee para las poblaciones nasa. En un tercer momento, las luchas de Quintín Lame volvieron a expresar abiertamente la resistencia indígena en esta subregión; sin embargo, sus demandas no lograron ser satisfechas sino hasta la fundación del CRIC. Finalmente, en la coyuntura de reactivación de la reforma agraria de los años setenta del siglo pasado, la fundación del CRIC reencauzó el proceso histórico de resistencia indígena a la violencia política, imprimiéndole nuevos sentidos.

El carácter fronterizo de Tierradentro es un elemento que mencioné en varios pasajes de este acápite. Dicho estatuto es, en primer lugar, el resultado de una intrincada geografía. Estas tierras permanecieron distantes y menos atractivas en términos económicos que aquellas que componen los valles del centro y norte del departamento del Cauca. A esta condición se agrega la resistencia indígena y, fundamentalmente, la puesta en marcha de una especial economía política de la diversidad. Como afirmé 
arriba, al articular esta región como espacio de otredad respecto del ser nacional fue posible establecer relaciones de explotación diferenciadas que se tradujeron en lógicas de colonialismo interno. Como postula Gnecco (2006), desde la década de 1940 también la antropología colombiana, con su proyecto de exaltación de la alteridad, resultó en una apología del aislamiento de las poblaciones indígenas. En efecto, las primeras generaciones de antropólogos representaron a Tierradentro como un territorio exótico -un racconto de esas etnografías puede encontrarse en Rappaport (2008, 54). La conformación de esta subregión como territorio de misión sintetiza esta condición de frontera que, según hemos visto, se reproduce parcialmente en el propio desarrollo del CRIC, que ha comenzado en el centro y norte del Cauca y ha logrado penetrar tardíamente en esta subregión. Planteado el escenario general de mi análisis, a continuación me detengo en las nuevas formas que adopta la resistencia a la violencia política en el marco del CRIC en Tierradentro.

\section{La recreación de la territorialidad comunitaria en Tierradentro: la resistencia del CRIC en cuatro dimensiones}

Para afrontar las múltiples formas de violencia política a las que se enfrentan las comunidades indígenas de Tierradentro, el CRIC ha desplegado un proceso de resistencia que constituye al mismo tiempo un modo de recrear la territorialidad comunitaria. Acorde el geógrafo brasilero Carlos Porto Gonçalves (2006), la territorialidad denota los procesos por medio de los cuales los actores sociales se afirman en el territorio. Todo proyecto de dominación necesita realizarse territorialmente; en este sentido, el orden social es también un orden territorial. Dado que el orden social nunca es un producto acabado, en todo territorio existen múltiples territorialidades, o también múltiples procesos de territorialización, que luchan por imponerse hegemónicamente.

Analizaré este proceso de recreación de la territorialidad comunitaria desplegado por el CRIC en Tierradentro a partir de cuatro dimensiones centrales, tal como anuncié en la introducción: la recuperación de los resguardos y los cabildos indígenas, la politización de la diferencia cultural y étnica, la construcción de un sistema educativo comunitario y el despliegue de procesos colectivos de planeación del desarrollo.

La recuperación de los territorios de resguardo articuló un espacio geográfico que remite a un proceso histórico de largo aliento. Las tierras recuperadas no fueron tituladas individualmente, a la usanza de la ANUC, sino que pasaron a ser propiedad de los órganos de autoridad colectiva, los cabildos, que las entregaron a los comuneros para que las usufructúen en calidad de adjudicatarios. Durante los primeros veinte años de funcionamiento del CRIC se recuperaron en Tierradentro 2.084has., 1.666 en Inzá y 417 en Belalcázar (Castillo Gómez 2009, 117 y 156). Sin embargo, el poder que la iglesia católica había conservado en esta subregión retrasó el trabajo de fortalecimiento de los cabildos que se había propuesto la organización. En 1990, a veinte años de la fundación del CRIC, Tierradentro seguía conservando una posición fronteriza para la organización indígena. A pesar de que esta era la zona con más cabildos indígenas, la mayor parte de ellos habían perdido autoridad y funcionaban descoordinadamente (E1).

El espacio que los cabildos dejaban libre era ocupado por las juntas de acción comunal, estructuras descentralizadas encargadas del manejo de algunos servicios públicos (art. 22 y 24 de la Ley 19 de 1958). Estas juntas estaban integradas por vecinos de cada distrito y se organizaban bajo las reglamentaciones expedidas por los consejos municipales. Desde los años sesenta del siglo XX, estas organizaciones habían servido al clientelismo político. En ese contexto, varias comunidades nasa comenzaron a identificarse como campesinas, desvinculándose de los resguardos indígenas. "Entonces, cada vez nos estábamos viviendo una estrechez, no solamente física, sino culturalmente", concluye Dídimo Perdomo, fundador de la asociación de cabildos Nasa Çxhâçxha (E3). 
Respondiendo a esta problemática, los cabildos de San Andrés, Santa Rosa, Yaquivá, Tumbichucue y La Gaitana, en el Municipio de Inzá, decidieron conformar la asociación de cabildos Juan Tama, primera de su tipo en el pueblo nasa. Posteriormente, se incluyeron el resguardo de Calderas y los cabildos nuevos de San Miguel, Turminá, Tum Dxi, Yaquivá y San Andrés de Pisimbalá (Asociación de Cabildos Juan Tama, 2005). En Páez, la organización de los cabildos, que había comenzado en 1994, se dilató por los efectos del terremoto. Las autoridades indígenas lograron conformar la asociación de cabildos Nasa Çxhâçxha en 1996, con un apoyo financiero parcial del Programa Tierradentro ${ }^{1}$ (E7; E3). Esta asociación agrupa a los 16 cabildos del muncipio (CRIC 2007). Las asociaciones de cabildos quedaron constituidas formalmente como entidades de derecho público, conforme al decreto 1088 de 1993.

Tabla 1: Resguardos indígenas en el Cauca. 2008.

\begin{tabular}{ccc}
\hline Zona & $\mathrm{N}^{\mathrm{o}}$ resguardos & Área (has.) \\
\hline Tierradentro & 24 & 208467,42 \\
Norte & 13 & 130264,01 \\
Centro & 6 & 35008,95 \\
Oriente & 10 & 34589,86 \\
Nororiente & 6 & 23558,25 \\
Occidente & 3 & 27426,02 \\
Reasentamientos post 1994 & 3 & 885,04 \\
Sur & 5 & 47804,39 \\
Pacífico & 9 & 66172,18 \\
Totales & 79 & 574176,12 \\
\hline
\end{tabular}

Cuando surgió el CRIC existían en el Cauca 28 resguardos. La lucha del movimiento indígena caucano ha logrado conformar 115 cabildos y 79 resguardos con 574.176,12 hectáreas legalizadas, un 18,6\% del área del departamento (CRIC 2007). Desde 1971, bajo este formato de acción colectiva, se recuperaron más de 250.000 ha. (PEBI 2004, 21), que hoy se rigen mediante la propiedad colectiva y se administran bajo la autoridad de los Cabildos indígenas. Como puede constatarse en la Tabla $\mathrm{N}^{\circ} 1$, Tierradentro sigue siendo la zona con mayor cantidad de cabildos indígenas, habiéndose sumado seis nuevos cabildos desde el surgimiento del CRIC hasta la fecha. Hoy Tierradentro se conforma por 24 resguardos, con 208.467,42has (CRIC y Asociación de Cabildos Nasa Çxhāçxha 2008).

Las recuperaciones de tierras fueron una respuesta a la clausura de la reforma agraria. Sin embargo, al ligar la tierra a un sistema de propiedad colectiva regido bajo órganos de autoridad comunitaria, el CRIC trascendió la concepción campesinista de la reforma agraria. Ya no se trata de conseguir tierras para producir, sino de recuperar unos territorios, los resguardos, que permiten recrear las relaciones sociales que configuran la comunidad indígena.

La segunda dimensión bajo la cual el CRIC ha logrado recrear la territorialidad comunitaria en Tierradentro es la politización de la diferencia étnica y cultural. Las conclusiones de los sucesivos congresos de la organización permiten constatar el pasaje desde una discursividad cercana al sindicalismo agrario hacia la politización de la diferencia cultural y étnica. Desde su segunda asamblea, la organización se posicionó en el marco de las luchas de los sectores populares, pero al mismo tiempo se encargó de

${ }^{1}$ El Programa Tierradentro fue una iniciativa de los resguardos de la zona en el contexto del terremoto que esta zona sufrió en 1994. Gracias al lobby internacional asumido por algunas figuras indígenas, este programa contó con el apoyo financiero de la Comunidad Europea, y tuvo por objetivo el desarrollo de obras de infraestructura y la capacitación de personal técnico (E7). 
dejar sentada su condición étnica particular (CRIC 1981). Las conclusiones del V Congreso del CRIC plantearon que la tierra era la base de la cultura indígena y dedujeron que recuperar la tierra era también recuperar la cultura y la identidad indígena (CRIC 1981, 93, 94 y 113). El fortalecimiento cultural resultó ser una tarea central de los primeros años de funcionamiento de las asociaciones de cabildos de Tierradentro. Dídimo Perdomo sostiene que "lo primero era reconocer quiénes éramos nosotros" (E3). Para eso Dídimo comenta que se hizo un trabajo de "autoestima" con la población indígena de Tierradentro, orientado al "auto-reconocimiento" de su etnicidad.

La recreación de la territorialidad indígena en Tierradentro se manifiesta en tercer lugar en la construcción de un sistema educativo comunitario. Los integrantes del CRIC en Tierradentro plantearon que la escuela resultaba una institución aculturizante, negadora del ser indígena y opuesta a las dinámicas comunitarias (E4, E11). La "escuela oficial" administrada por la iglesia católica promovía el desapego por los trabajos agrícolas y por las prácticas culturales indígenas, y conspiraba contra el uso de las lenguas maternas (E2; CIIIT 2015).

Con el objetivo de desarticular esta función colonizadora de la escuela oficial, el CRIC emprendió un proceso de práctica y reflexión sobre la educación que comenzó en 1978 con la creación del Programa de Educación Bilingüe (PEB). La primera escuela administrada por el CRIC en Tierradentro se estableció en la vereda de El Cabuyo, resguardo de Vitoncó. El objetivo de esta escuela era "generar una educación para defenderse colectivamente como indígenas y no una educación para superarse individualmente" (PEBI 2004, 42). Las escuelas funcionaron como espacios abiertos a la comunidad y sus programas de estudio fueron definidos en instancias colectivas. Desde 1994, el PEB impulsó los Proyectos Educativos Comunitarios, una alternativa educativa que pretendía construirse desde las propias comunidades y a partir de sus conocimientos tradicionales (Ramos Pacho y Rojas Curieux 2005). En el IX Congreso, el CRIC se propuso desarrollar uno de estos proyectos en cada resguardo para fortalecer el modelo educativo propio.

En Tierradentro, las dos asociaciones de cabildos impulsaron la construcción de los Proyectos Educativos Comunitarios en cada resguardo. En el 2010, después de una multitudinaria marcha indígena, el Ministerio de Educación Nacional expidió el decreto 2500 que habilita a las organizaciones y autoridades indígenas la gestión de los centros escolares. Bajo esta norma, el CRIC ha logrado administrar la educación en los territorios indígenas del departamento, abarcando más de 16.000 estudiantes de los 9 pueblos indígenas y más de 800 maestros (Bolaños, Tattay, Pancho 2009, 159). De este modo, se ha puesto término a la administración eclesiástica de la educación en Tierradentro.

Para completar el sistema educativo comunitario en el nivel superior, el CRIC creó la Universidad Autónoma Indígena Intercultural (UAIIN). Esta iniciativa comenzó a funcionar de hecho alrededor de 1995, pero fue formalizada en Junta Directiva del CRIC en el 2003. La universidad tiene por objetivo construir una propuesta que contribuya a la formación de activistas locales dentro de su contexto comunitario. En este punto, la UAIIN se diferencia de otras universidades indígenas latinoamericanas ya que no se enfoca únicamente en la formación personal del estudiante, sino que se piensa como un espacio potenciador de los proyectos de las comunidades de base. Los programas de formación han sido elaborados de acuerdo a las necesidades prioritarias del contexto comunitario y forman parte de una estrategia de fortalecimiento político y organizativo del CRIC (E5).

En Tierradentro residen más de 178 estudiantes de la UAIIN (CIIIT 2015), lo que equivale al $17,8 \%$ de la matrícula total. Las asociaciones de cabildos de Tierradentro en concordancia con la universidad han creado en el 2009 el programa de estudios de Desarrollo Comunitario y el de Lenguas Originarias, que se suma al Programa de Licenciatura en Pedagogía Comunitaria operativo desde 1997. Estos programas son pensados como una estrategia para la defensa integral del territorio frente a las amenazas existentes, entre las que se destacan los proyectos extractivos de las empresas multinacionales, los planes de ordenación territorial del Estado y el debilitamiento de las estructuras de pensamiento que se nutren de la lengua materna (E4, E9, E13). 
Desde los años ochenta, la organización ha impulsado iniciativas que se orientan a la planeación colectiva del desarrollo comunitario, cuarta dimensión en la que se expresa la recreación de la territorialidad que defiende el CRIC. La primera de estas iniciativas se formalizó en 1980 con el llamado "Proyecto Nasa" en Toribío, que constituyó una respuesta a la situación de violencia política generalizada que experimentaban las comunidades del norte del departamento (Hernández Delgado 2004). Este proyecto tomaba elementos de la tradición indígena nasa, pero al mismo tiempo se nutría de los preceptos de la teología de la liberación que estaba en auge desde la segunda Conferencia General del Episcopado Latinoamericano realizada en 1968 en Medellín. Fruto de una serie de deliberaciones colectivas, maduraron programas que comprendieron las áreas de producción, familia, vivienda, salud, educación, evangelización, trabajo comunitario, tiendas y empresas comunitarias. Siguiendo el ejemplo del Proyecto Nasa se crearon: en 1987, el Proyecto Global de Jambaló; en 1990, el "Proyecto Unidad Páez" de Miranda y el "Proyecto Integral" de Caloto; en 1991, el "Proyecto Cxa Cxa Wala" de Corinto y el "Proyecto Yu'lucx" de Santander y Buenos Aires.

Actualmente, el movimiento indígena hace referencia a los ejercicios colectivos de planeación del desarrollo bajo el concepto "Planes de Vida". Según me comentó Guillermo Santamaría, el coordinador del equipo Territorio y Naturaleza de la Asociación de cabildos Nasa Çxhāçxha, este término apareció por primera vez a mediados de los años ochenta en las comunidades afrocolombianas de La Balsa, en el municipio de Buenos Aires, afectadas por la construcción de la represa La Salvajina sobre el río Cauca (E6). En el X Congreso del CRIC, celebrado en Silvia en 1997, se recomendó a los cabildos indígenas utilizar el término "Plan de Vida" en vez de "Plan de Desarrollo", con el objetivo de construir el futuro "desde nuestra propia lógica" (Asociación Nasa Çxhâçxha 2015, 3). Esta estrategia se propone recrear las condiciones económicas, sociales y culturales necesarias para la existencia de los pueblos indígenas, articulándose con los distintos proyectos que lleva adelante el CRIC.

En Tierradentro, las asociaciones de cabildos reunieron a los médicos tradicionales y a los mayores para reflexionar sobre las formas de planeación existentes en la cultura nasa. En estos ejercicios comunitarios, los intelectuales orgánicos del CRIC trabajaron desde las memorias indígenas para reinterpretar el concepto occidental de desarrollo. Desde la posición fronteriza que los constituye, los médicos tradicionales, los mayores y las autoridades, junto a los colaboradores, operaron una traducción intercultural de inusitada potencialidad política (E22). El plan de vida fue definido como un proceso colectivo de "reflexión-acción-reflexión fundamentado en el pensamiento indígena" (Asociación Nasa Çxhâçxha 2015, 6). A diferencia de los planes estatales, que tal como ha planteado Arturo Escobar (1987, 115) suelen adolecer de una visión economicista del desarrollo y de la propia existencia humana, "para los pueblos indígenas primero está la fuerza espiritual como fuente de vida y el territorio como madre; [ya que] sin estos principios la existencia no es posible" (CRIC 2007, 24). La estrategia de los planes de vida comunitarios significó un cuestionamiento a la difundida concepción del desarrollo que lo postula como un proceso evolutivo indefectiblemente ligado al mercado capitalista. Representa, a su vez, un intento por desarticular el colonialismo interno al que fue sometido el pueblo nasa de Tierradentro.

\section{Conclusiones}

En el desarrollo de este trabajo analicé la resistencia a la violencia política del pueblo nasa de Tierradentro en un abordaje de larga duración. Esta perspectiva sociohistórica me ha permitido identificar una serie de coyunturas bajo las cuales dicha resistencia ha adoptado distintas estrategias. Inscribí la emergencia del CRIC en esta temporalidad de largo aliento y me detuve en las formas bajo las cuales las instancias locales afiliadas a esta organización han desarrollado su resistencia. Afirmé que la resistencia a la violencia política que el CRIC practica en Tierradentro constituye un proceso de recreación de la territorialidad comunitaria. Finalmente, postulé que la recreación de esta territorialidad se ha desplegado en cuatro dimensiones principales que analicé individualmente: la recuperación y ampliación de los 
resguardos y de los cabildos indígenas, la politización de la diferencia cultural y étnica, la construcción de un sistema educativo comunitario y la elaboración de planes colectivos de desarrollo.

El movimiento indígena colombiano ha logrado que la territorialidad comunitaria adquiriese un estatuto legal. Gracias a la participación de dos representantes indígenas en la Asamblea Nacional Constituyente de 1991, el resguardo quedó reconocido bajo la figura de las entidades territoriales indígenas (art. 329), garantizando su autonomía (art. 1). A su vez, la nueva Constitución estableció el derecho indígena al territorio (art. 63) y al autogobierno (art. 287 y 330), y dejó asentado el derecho a ejercer funciones jurisdiccionales de acuerdo a las normas consuetudinarias (art. 246). Siguiendo los principios constitucionales se dictaron normativas orientadas a garantizar la constitución y ampliación de los resguardos (decreto 2164 de 1995) y se establecieron procedimientos para la conformación de nuevos cabildos y de asociaciones de cabildos indígenas (decreto 1088 de 1993). En el 2014, las organizaciones indígenas consiguieron que se expidiera el decreto 1953 por el cual se creó un régimen especial con el fin de poner en funcionamiento los territorios indígenas. Desde entonces, estos territorios tienen derecho a gobernarse por sus propias autoridades y a definir políticas económicas, sociales, ambientales y culturales, contando con una adjudicación presupuestaria estatal.

Como ha señalado Cristóbal Gnecco (2006), el reconocimiento de la territorialidad comunitaria debe ubicarse en la intersección entre las demandas de territorialización autónoma de las organizaciones indígenas y las necesidades del capital postnacional. El multiculturalismo neoliberal instaurado por la nueva Constitución, reitera la segregación moderna de los indígenas bajo un nuevo signo. Lo que Astrid Ulloa llama "nativos ecológicos" (Ulloa citado en Gnecco 2006, 22), constituye una creación discursiva que compone a los indígenas como guardianes de territorios biodiversos que se ubican en una nueva frontera "levantada entre naturaleza y cultura por los discursos ambientalistas". Estos sujetos son ahora los encargados de negociar el acceso a sus recursos directamente con el capital, evitando la intervención del Estado.

La recreación de la territorialidad comunitaria ha alcanzado en los albores del siglo XXI una magnitud insospechada. Sin embargo, las condiciones de vida de la población de Tierradentro continúan siendo preocupantes. En las zonas rurales del Cauca, la población con necesidades básicas insatisfechas supera el 60\%, y en Tierradentro alcanza el 66,3\%, según los datos del DANE. En promedio, las familias indígenas del Cauca disponen de 7.37ha. (CRIC 2007, 366). Pero en Tierradentro las fuertes pendientes del terreno, las áreas protegidas, los humedales, los bosques de montaña, las tierras eriales y las áreas urbanas reducen las tierras aptas para el trabajo agrícola hasta arrojar un saldo de 5,6ha. cultivables por familia. Las asociaciones de cabildos de la zona consideran que es necesario ampliar el territorio en 47.114ha. para lograr subsistir en condiciones dignas de vida.

La falta de tierras para las comunidades indígenas de Tierradentro podría profundizarse en el corto plazo. Los acuerdos de paz entre el gobierno colombiano y las FARC contemplan la construcción de "Zonas de Reserva Campesina", que en algunos casos se superponen con los territorios reclamados como propios por la organización indígena. ${ }^{2}$ Desde 1993, los campesinos han comenzado a organizarse a nivel municipal, fundando en 1997 la Asociación Campesina del Municipio de Inzá (ACIT). La potencial conquista de tierras por parte de esta organización podría traducirse en una nueva forma de desintegración de los resguardos indígenas, configurando una amenaza más a la recreación de la territorialidad comunitaria que defiende el CRIC en Tierradentro.

\footnotetext{
2 La creación de las zonas de reserva campesina, demanda histórica de las comunidades campesinas colombianas, se incorporó a la Ley 160 de 1994 -reglamentada en 1996 con el decreto 1777 (Art. 1). Como sostiene Darío Fajardo Montaña (2000), la figura surge como parte del afianzamiento de la reforma agraria marginal, ya que su existencia se reduce a las áreas de colonización y de baldíos. Los acuerdos de paz contemplan la creación de nuevas zonas de reserva campesina, concebidas como “...iniciativas agrarias que contribuyen a la construcción de la paz...” (Acuerdo final punto 1.1.10, 20), en el marco de la reforma rural integral.
} 


\section{Referencias}

\section{Fuentes impresas}

Albán, Álvaro. 2011. "Reforma y contrarreforma agraria en Colombia". Revista de Economía Institucional, 13(24): 327-356.

Ansaldi, Waldo. 2002. "De abejas, de arquitectos y de carpinteros. A propósito de "Historia y Ciencias Sociales", un artículo de Carlos Astarita." Sociohistórica, 11-12: 13-34.

Ansaldi, Waldo y Alberto, Mariana. 2014. "Muchos hablan de ella, pocos piensan en ella. Una agenda posible para explicar la apelación a la violencia política en América Latina". En América Latina. Tiempos de violencias, compilado por Waldo Ansaldi y Verónica Giordano, 27-46. Buenos Aires: Ariel.

Ansaldi, Waldo y Giordano, Verónica. 2012. América Latina. La construcción del orden. Tomo 1, Buenos Aires, Argentina: Ariel.

Bolaños, Graciela; Tattay, Libia y Pancho, Avelina. 2009. "Universidad Autónoma, Indígena e Intercultural (UAIIN): Un proceso para fortalecer la educación propia y comunitaria en el marco de la interculturalidad". En Instituciones Interculturales de Educación Superior en América Latina. Procesos de construcción, logros, innovaciones y desafios, coordinado por Daniel Mato, 155-190. Caracas: UNESCO-IESALC.

Bonilla, Víctor Daniel. 1982. Historia política de los paeces. Bogotá: Colombia Nuestra.

Briones, Claudia; Delrio, Walter; Lanusse, Paula; Lazzari, Axel; Szluc, Andrea y Vivaldi, Ana. 2006. "Diversidad cultural e interculturalidad como construcciones sociohistóricas". En Diversidad cultural e interculturalidad, compilado por Aldo Amegeiras y Elisa Jure, 255-264. Buenos Aires: Prometeo libros Universidad Nacional de General Sarmiento.

Castillo Cárdenas, Gonzalo. 1971. "Manuel Quintín Lame: luchador e intelectual indígena del Siglo XX”. En En defensa de mi raz̧a, Manuel Quintín Lame. Bogotá: Rosca de Investigación y Acción Social.

Castillo Gómez, Luís Carlos. 2009. Etnicidad y nación. El desafío de la diversidad en Colombia. Cali: Programa editorial de la Universidad del Valle.

Centro Nacional de Memoria Histórica-CNMH. 2012. Nuestra vida ha sido nuestra lucha. Resistencia y memoria en el Cauca indígena. Colombia: Taurus.

Departamento Administrativo Nacional de Estadística -DANE. 2005. Censo Nacional. Disponible en: http://www.dane.gov.co/index.php/esp/poblacion-y-registros-vitales/censos/censo-2005/123-

demograficas/censos/2694-sistema-de-consulta

Escobar, Arturo. 1987. Power and Visibility: The Invention and Management of Development in the Third World. Estados Unidos: University of California.

Espinosa Arango, Mónica L. 2007. "Memoria cultural y el continuo del genocidio: lo indígena en Colombia". Antipoda, 5: 53-73.

Fajardo Montaña, Darío. 2000. "Las Zonas de Reserva Campesina: ¿Estrategia de Desarrollo Regional y contra el Desplazamiento?”. En: $M A M A C O C A$. Disponible en:

http://www.mamacoca.org/Compendio regional/Dario Fajardo\%20.htm, consultado el 11/4/2017).

Fajardo Montaña, Darío. 2015. "Colombia: agricultura y capitalismo". En Capitalimo: tierra y poder en América Latina (1982-2012). Vol. II, coordinado por Guillermo Almeyra, Luciano Concheiro Bórquez, João Márcio Mendes Pereira y Carlos Walter Porto Gonçalves, 65-122. México DF: CLACSO.

Findji, María Teresa y Rojas, José María. 1985. Territorio, economia y sociedad páez: Cali: Universidad del Valle. Findji, Teresa. 1978. Elementos para el estudio de los resguardos indígenas del Cauca. Censo indígena del Cauca, 1972. Colombia: DANE.

Foucault, Michel. 1986. Las redes del poder. Fabrenheit 450, 1: 13-19.

Foucault, Michel. 2000. Un diálogo sobre el poder y otras conversaciones. Madrid: Alianza Editorial.

Foucault, Michel. 2007. La arqueologia del saber. Buenos Aires: Siglo XXI.

Foucault, Michel. 2008. Defender la sociedad. Buenos Aires: Fondo de Cultura Económica. 
Galtung, Johan. 1998. Tras la violencia, 3R: reconstrucción, reconciliación y resolución. Afrontando los efectos visibles e invisibles de la guerra y la violencia. Bilbao: Bakeaz - Gernika Gogoratuz.

Gnecco, Cristóbal. 2006. "Territorio y alteridad étnica: fragmento para una genealogía". En (Des)territorialidades y (No)lugares, editado por Diego Herrera y Emilio Piazzini, 221-246. Medellín: La Carreta Social.

Gómez, Herinaldy y Ruíz, Carlos Ariel. 1997. Los paeces: gente territorio. Metáfora que perdura. Colombia: Universidad del Cauca.

González Casanova, Pablo. 1978. "América Latina: las críticas a las ciencias sociales y las tareas inmediatas". Estudios Sociales Centroamericanos, 21: 209-224.

González, Fernan E.; Bolívar, Ingrid, y Vázquez, Teófilo. 2002. Violencia política en Colombia. De la nación fragmentada a la construcción del Estado. Bogotá: CINEP.

Gros, Christian. 1991. Colombia Indigena. Identidad cultural y cambio social. Bogotá: CEREC.

Hernández Delgado, Esperanza. 2004. Resistencia civil artesana de pa\%. Experiencias indígenas, Afrodescendientes y campesinas. Bogotá: Editorial de la Universidad Javeriana.

Instituto Geográfico Agustín Codazzi -IGAC. 2012. Atlas de la distribución de la propiedad rural en Colombia. Bogotá: Imprenta Nacional de Colombia.

Lemaitre Ripoll, Julieta. 2013. “iViva nuestro derecho! Quintín Lame y el legalismo popular”. En La Quintiada (1912-1925): la rebelión indígena liderada por Manuel Quintín Lame en el Cauca: recopilación de fuentes primarias, 221-260. Bogotá, Colombia: Universidad de los Andes.

Leone, Miguel. 2017. Prácticas de pastoral aborigen y juridización de derechos indígenas en Argentina. Un análisis de la región del Chaco (1965-1994), tesis doctoral. Buenos Aires: UNGS/IDES mimeo.

Levalle, Sebastián (2018). Resistencia a la violencia política y defensa de la territorialidad comunitaria en el departamento del Cauca, Colombia (1971-2012). Sociedad y Economía, 34: 251-266.

Programa de Educación Bilingüe Intercultural -PEBI. 2004. ¿Qué pasaría si la escuela...? Treinta años de construcción educativa. Colombia: Consejo Regional Indígena del Cauca.

Peñaranda, Daniel Ricardo. 2012. "Las guerras de los años ochenta y la resistencia contra los actores armados". En "Nuestra vida ba sido nuestra lucha" Resistencia y memoria en el Cauca indígena, 19-50. Colombia: Centro Nacional de Memoria Histórica.

Porto-Gonçalves, Caros Walter. 2009. Territorialidades y luchas por el territorio en América Latina: geografía de los movimientos sociales en América Latina. Caracas: IVIC.

Pumarada Cruz, Yeseña C. 2013. Othering Modernization: the Nasa Margins of Colombia (1890-1930s), tesis doctoral en filosofia, Universidad de Wisconsin-Madison. Recuperado de: https://www.academia.edu/3569461/Othering_Modernization_the_Nasa_Margins_of_Colombia_188 0-1940.

Ramos Pacho, Abelardo y Rojas Curieux, Tulio. 2005. "Educación escolar, vida comunitaria y uso de las lenguas: reflexiones sobre el proceso en el pueblo nasa (paez)". Revista Colombiana de Educación, 48: 70-90. Rappaport, Joanne. 1990. The politics of memory. Native historical interpretation in the Colombian Andes. Cambridege: Cambridge University Press.

Rappaport, Joanne. 2008. Utopías interculturales. Intelectuales públicos, experimentos con la cultura y pluralismo étnico en Colombia. Bogotá: Editorial Universidad del Rosario.

Roattino, Enzo. 1986. Alvaro Ulcue Nasa Pal. Sangre india para una tierra nueva. Bogotá: CINEP.

Rodríguez, Gina Paola. 2016. "El Leviatán en la sombra. Violencia parainstitucional en Colombia (19452010). Desafíos para la teoría”. Actas de las I Jornadas Nacionales e Internacionales en Estudios Latinoamericanos y del Caribe.

Rojas, Axel y Castillo, Elisabeth Guzmán. 2005. Educar a los otros. Estado, politicas educativas y diferencia cultural en Colombia. Cali: Universidad del Cauca.

Sánchez, Luís Carlos; Vargas, Andrés R. y Vásquez, Teófilo. 2011. "Las diversas trayectorias de la guerra. Un análisis subregional". En Una vieja guerra en un nuevo contexto. Conflicto y territorio en el sur de Colombia, editado por Teófilo Vásquez, Andrés Vargas y Jorge A. Restrepo, 35-298. Bogotá: Editorial Javeriana. 
Sistema Integrado de Monitoreo de Cultivos Ilícitos -SIMCI. 2007. Colombia: monitoreo de cultivos de coca, Oficina de Naciones Unidas Contra la Droga y el Delito. Recuperado de: http://www.biesimci.org/Documentos/Documentos.html

Skocpol, Theda (ed.). 1991. Vision and Method in Historical Sociology. Nueva York: Cambridge University Press.

Stern, Steve, (comp.). 1990. Resistencia, rebelión y conciencia campesina en los Andes. Siglos XVIII al XX. Lima: IEP.

Tilly, Charles. 1991. Grandes estructuras, procesos amplios, comparaciones enormes. Madrid: Alianza.

Tilly, Charles. 1998. "Conflicto político y cambio social”. En Los movimientos sociales. Transformaciones políticas y cambio cultural, editado por Pedro Ibarra y Benjamín Tejerina. Valladolid: Trotta.

Zamosc, León. 1984. Los Usuarios Campesinos y las luchas por la tierra en los años 70. Bogotá: CINEP.

\section{Documentos}

Asociación de Cabildos Juan Tama. 2005. Plan de Vida de la Asociación de Cabildos Juan Tama. Pensamiento ancestral:por la construcción del tejido social y el fortalecimiento de las relaciones interculturales, Tierradentro, Colombia: Asociación de Cabildos Juan Tama.

Cabildo de Guambía. 1980. Manifiesto Guambiano. Recuperado de: nacionmisak.wordpress.com/manifiesto-guambiano/

Centro Indígena de Investigaciones Interculturales de Tierradentro -CIIIT. 2015. Contextos y Trayectorias del CIIIT en la zona Tierradentro-Relatoría-, Resguardo de Santa Rosa, 14 y 15 de agosto.

Consejo Regional Indígena del Cauca -CRIC- y Asociación de Cabildos Nasa Çxhāçxha. 2008. Elementos para la estimación de tierras aptas para aprovechamiento agrícola en territorios indigenas del departamento del Cauca, Octubre.

Consejo Regional Indígena del Cauca -CRIC. 2007. Plan de vida regional de los pueblos indígenas del Cauca: "Reconstruir el pasado para vivir el presente y reafirmar el futuro".

Consejo Regional Indígena del Cauca -CRIC. 1990. "Historia del CRIC", Programa de Capacitación, Popayán, Colombia, junio.

Consejo Regional Indígena del Cauca -CRIC. 1981. Consejo Regional Indígena del Cauca. Diez años de lucha. Historia y documentos. Bogotá: CINEP.

\section{Referencias orales}

E1. Entrevista a Arnulfo Guegia, ex integrante de la Asociación de Cabildos Juan Tama, Belalcázar, Páez, 26/03/2016.

E2. Entrevista a Carlos Guegia, integrante del CIIIT, Mosoco, Páez, Tierradentro, 23/02/2013.

E3. Entrevista a Dídimo Perdomo, fundador de la Asociación de Cabildos Nasa Çxhâçxha y ex Coordinador de educación de Tierradentro, Belalcázar, Páez, 20/02/2013.

E4. Entrevista a Gentil Guegia, Segundo Coordinador del CIIIT, Entrevista telefónica, 2012.

E5. Entrevista a Graciela Bolaños, ex Coordinadora de la UAIIN y del PEBI, Popayán, 13/02/2013.

E6. Entrevista a Guillermo Santamaría, integrante del equipo de Territorio y Naturaleza, Asociación de Cabildos Nasa Çxhâçxha, Belalcázar, Páez, 20/02/2013.

E7. Entrevista a Guillermo Santamaría, integrante del equipo de Territorio y Naturaleza, Asociación de Cabildos Nasa Çxhâçxha, Belalcázar, Páez, 05/04/2016.

E8. Entrevista a Guillermo Santamaría, integrante del equipo de Territorio y Naturaleza, Asociación de Cabildos Nasa Çxhâçxha, 10/04/2016.

E9. Entrevista a Huber Castro, coordinador de orientadores en el programa de Lenguas Originarias de la UAIIN, integrante del CIIIT, Páez, 26/03/2016. 
E10. Entrevista a Jesús "Chucho" Tenorio, ex presidente de la Asociación de Cabildos Juan Tama, Mosoco, Páez, 07/04/2016.

E11. Entrevista a José Domingo Caldón, integrante del equipo de formación política del CRIC, Popayán, $01 / 04 / 2016$.

E12. Entrevista a Marina Campos, ex coordinadora de la Guardia Indígena de Belalcázar, ex integrante del equipo de familia, actual integrante del Equipos de Salud, 09/04/2016.

E13. Entrevista a Natalia Caicedo Vázquez, colaboradora del CIIIT, Bogotá, 21/02/2013. 